\title{
EDITORIAL
}

\section{UNA SITUACIÓN DE CUIDADO COMO HERRAMIENTA PARA SU ENSEÑANZA}

\author{
A care situation as a tool for teaching
}

El Cuidado es Amor

I 18 de noviembre, apenas ayer se festejó su cumpleaños, me extrañó no verla en el jardín tomándole fotos a la nueva flor del mismo, o meciéndose en el columpio comiendo uvas, descalza y un poco despeinada. Entré a la casa con ganas de toparme con una realidad diferente, pero no, la expectativa aún continúa distante, me observó y con su sonrisa transparente me hizo entender que todo valía la pena, tantos desvelos, tanto cansancio, tantas lágrimas, tenía la comida lista y no pude hacer nada más que abrazarla, hacía todo por hacerme sentir bien, hacía como que nada pasaba, me contaba como estuvo el día mientras bromeaba y se reía como siempre y aunque por dentro yo quería Ilorar, externamente sonreía por su gracia al contar los chistes diarios que salen en el periódico. ¿Cómo es posible? me preguntaba, ¿que a una mujer como ella le pase esto?, pero segundos más tarde lo comprendí mientras ella jugaba con su cabello, éste se desprendió de repente y sin hacer mayor alarde ella lo ocultó, por supuesto fingí no haberla visto, lo comprendí: Ella podía con esto y si ella podía, nada más importaba, yo también podía hacerlo. Fui al baño me mojé la cara y regresé a la cocina, en la mesa encontré una máquina para cortar el cabello, me miró y me dijo ya es tiempo, fingí que no me importaba pero una parte de mí se ponía a temblar cada vez que uno de sus rubios cabellos caía al suelo, al terminar de cortar su pelo volteó hacia mí y me preguntó: ¿Alexa, ya no soy bonita?, le sonreí con mucha ternura y aunque ella se miraba con cierta rareza en el espejo, no pude evitar percatarme de que era la mujer más hermosa del mundo, me di cuenta que ya no quería ser aquella chica esbelta con ojos de color y cabello largo, no, ahora quería ser como ella, la mujer que no tiene pelo y que le hace muecas a los bebés, esa mujer que ama la vida. Pasó la tarde dormida y yo estuve toda la tarde mirándola, después de todo llegué a una conclusión, ¿Qué es el cuidado, si no es amor?

\section{Est. Lic. Enf. Edith Alexa Peña Gracia}

Una inquietud frecuente de los docentes de enfermería tiene que ver con la enseñanza del cuidado, son preguntas reiteradas en reuniones o sesiones de reflexión ¿Como se enseña a cuidar? ¿Cómo se logra que el estudiante reconozca la importancia de las expresiones y comportamientos de cuidado? Ese cuidado que Boykin y Schoenhofer señalan como "la presencia intencional y auténtica de la enfermera con otra persona que se reconoce como persona que vive el cuidado y crece en el cuidado" que además se considera la esencia de la enfermería desde la perspectiva de Leninger ${ }^{(1)}$ y Watson ${ }^{(2)}$. Por lo tanto, las experiencias motivantes dentro del proceso enseñanza-aprendizaje de enfermería deben desarrollar la concepción del cuidado como objeto de estudio sobre el que girará la formación.

Es importante retomar el principio de que la persona es cuidadora en virtud de su humanidad y en ello se propone fundamentar la enseñanza del cuidado, lo que supone un compromiso a conocerse a si mismo y al otro, como personas de cuidado que se expresan a través de las experiencias de vida que se viven momento a momento y constituye una vivencia única.

Para la enseñanza del cuidado se sugieren diversas estrategias que le permitan a quienes están en formación fortalecerse en él, entre las que destaca la utilización de situaciones de enfermería que es una experiencia vivida y compartida que permite al estudiante conocer a la persona como cuidadora y vive el momento único que le brinda la oportunidad para afirmar los valores y el amor por la disciplina.

En el departamento de Enfermería de la Universidad de Sonora, dentro de la formación de alumnos de pregrado en su primer acercamiento al contenido conceptual-epistemológico de enfermería, se plantea al estudiante que aún no vive las prácticas clínicas, que construya una situación de enfermería experimentada en su contexto cotidiano, sustentado en el hecho de que todas las personas son cuidadoras y con el propósito de identificar en la vivencia los ingredientes del cuidado, además de lograr una primera comprensión de la naturaleza de las situaciones de enfermería. De ese ejercicio surgió la construcción compartida que muestra que las personas desarrollamos expresiones de nosotros mismos como personas de cuidado en forma continua y natural y, además, se expresa a través de un relato que permite la reflexión sobre el conocimiento personal y artístico contenido en el mismo.

\section{M.C. Eva Angelina Hernández Villa \\ Maestra de tiempo completo \\ Departamento de Enfermería \\ Universidad de Sonora \\ eva_angelina_h@hotmail.com}

1. Raile M. Modelos y teorías de Enfermería. Octava ed. Madrid, España: Elsevier-Mosby; 2015.
2. Watson J. The Philosophy and Science of Caring. Rev. ed. ed. Boulder, Colorado: University Press of Colorado; 2008. 